\title{
Proyección del Hospital de San José ante las nuevas normas de atención médica
}

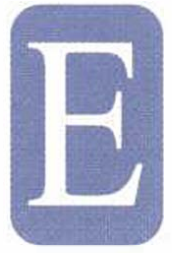

I panorama de la salud en Colombia cambió con la implementación de la Ley $1(00$ de 1993. de modo que los médicos tuvimos que ajustar nuestro ejercicio profesional a lo establecido por lass normativas vigentes ante la imperiosa necesidad de mejoramiento continuo, en la cual hemos tenido cue involucramos y evolucionar para evitar la desactualización médico/administrativa y la falta de competitividad.

Por esta razón el Hospital de San José, como institución prestadora de servicios de salud, ha tenido cue realizar grandes cambios. Así, las nuevas reformas y proyectos de ley han influido en el desarrollo de las actividades propias del hospital.

Circunscritos en este ámbito, es muy importante identificar el sistema de inspección, vigilancia y control del sector salud, el cual establece una serie de objetivos, actividades y metas dirigidos al mejoramiento de la calidad. la oportunidad y el trato digno en la prestación de los servicios de salud.

Sin embargo, la falta de equidad de la Ley 100 de 1993. con su reglamentación defectuosa y una integración vertical, en donde el Estado le está permitiendo a las EPS la creación de sus propias IPS (sin un adecuado sistema de garantía de (alidad), ha desvirtuado el objetivo inicial que pretendía prestar servicios de salud basados en principios de calidad. Esto genera la incertidumbre de continuidad y permanencia dentro del sistema, de los diferentes planes complementarios que brindan algunas entidades, incluso acpuellas que cuentan con planes de medicina prepagada, situación que sería conveniente a fin de captar al usuario con suficientes recursos económicos que le permita acceder al servicio médico particular, en calidad de "paciente institucional", como se le denomina en el hospital.

El hospital debe continuar en el proceso de mejoralmiento que inició, con el fin de cumplir las expectativas, alcanzar las metas y fortalecerse como una institución prestadora de servicios de salud, que impacte tanto al cliente interno como externo y a sus diferentes proveedores; de esta manera logrará permanecer en el medio y se preparará, desde el punto de vista de infraestructura, tecnología y capacitación, para enfrentar las diferentes reformas que están en proceso, sin que el dinero sea el único factor de permanencia.

Desde sus comienzos, el Hospital de San José se ha caracterizado por ser una institución de alta trayectoria académica e investigativa, a la vanguardia de muchas actividades científicas. Ello le permite proyectarse al futurocomo una entidad sólida, en proceso de mejoramiento continuo, que debe superar sus dificultades económicas, mejorar el flujo de caja y realizar innovaciones tecnológicas y estructurales para liderar el proceso de atención en salud. Además, debe continuar con la gestión médica y sus buenos resultados en los indicadores de gestióncalidad y realizar más actividades tendientes al conocimiento de las fortalezas y debilidades para buscar estrategias de mejoramiento en equipo.

Otra de las oportunidades es ampliar las formas de negociación actuales e ingresar a la contratación por capitación, que específicamente estaría enfocada en los niveles 3 y 4 de complejidad: ello es posible gracias a cue contamos con la tecnología de punta cjue nos permite ofrecer servicios integrales según las necesidades de nuestros usuarios.

En cuanto al mercadeo en salud, como parte fundamental de la gestión dentro de la planeación, es importante contar con mecanismos cjue generen la ampliación de productos a través de actividades como benchmarking y otras similares, alianzas estratégicas con las diferentes empresals aseguradoras y otras instituciones prestadoras de servicios en salud, e incluso proyectarse a corto plazo en la creación de una empresa promotora de salud.

Por otra parte, las mejoras locativas realizadas han impulsado la institución y son un atractivo más parara cauttivar a los usuarios, pues la ubicación geográlica del hospital y las dificultades para su acceso hacian cue muchos pacientes se abstuvieran de acudir al hospital.

Laime Didziulis (J., M.D). Directora Médica, Hospital de San José 